Malkanthie, M.A.A., Kelum, W.G.S., KJM, 2021, 10 (01)

\title{
Exploration of How Appearance Management is Used to Improve the Self Esteem by Urban Silver Aged Women in Sri Lanka
}

\author{
Malkanthie M.A.A. ${ }^{1}$, Kelum W.G.S. ${ }^{2}$ \\ 1,2 University of Sri Jayewardenepura, Sri Lanka \\ ${ }^{1}$ maamalkanthie@sjp.ac.lk, ${ }^{2}$ kelumg@sjp.ac.lk
}

\begin{abstract}
From 1981 to 2012, within 31 years, the Sri Lankan elderly population has doubled. It is estimated that one in four Sri Lankans will be elderly by the year 2041. One of the mistakes done by marketers is neglecting this group by thinking that they have low income and spend less money. Even though they have less income, they are not in poverty compared to the population under age 34. Silver aged population (age 50+) experience physical and mental changes during this period due to body postures, wrinkles, and changes in hair color and skin tones. Despite the bodily changes associated with aging, previous studies reported that the importance of appearance did not decrease with age, and appearance was more important for women than for men. It is the nature of humans that want to appear as young and beautiful as possible regardless of age. Hence the purpose of this research is to explore how appearance management is used to improve the self-esteem in old age. This research adopted the inductive approach since this research is trying to understand the hidden behaviors and psychological matters of women who are passing the silver age. The population of this study was considered as urban women, over fifty years of age in Sri Lanka and the individual level was used since the researcher asked questions from women individually to discover their behavior. Clothing is a visual representation of the self, women use articles of dress to construct and maintain their appearance, cognitively coherent with groups. Individuals manage appearance to represent their image. Fashion is closely linked to the emotional well-being of women. The women in this research used fashion as both social and symbolic capital to classify themselves concerning perceived social categories such as friends, peers, and their projected future self.
\end{abstract}

Keywords: Appearance Management, Self Esteem, Fashion Involvement, Silver-Aged Women

Copyright: (C) 2021 Malkanthie M.A.A, Kelum W.G.S. This is an open access article distributed under the Creative Commons Attribution License, which permits unrestricted use, distribution, and reproduction in any medium, provided the original work is properly cited.

Funding Agency: This work was financially supported by University of Sri Jayewardenepura [grant number ASP/01/RE/MGT/2019/37].

Correspondence: maamalkanthie@sjp.ac.lk

ORCID of authors: Malkanthie M.A.A- https://orcid.org/0000-0002-0119-3516

Kelum W.G.S. - https://orcid.org/0000-0002-7722-1034

DOI: http://doi.org/10.4038/kjm.v10i1.7668 


\section{Introduction}

The elderly population in Sri Lanka is defined as those who have completed sixty years of age and above (Maduwage,2019). It varies from country to country. Some countries consider it as 55+ age group. The fastest-growing elderly population is due to longer life expectancy and baby boomers entering this age group. "Sri Lankan elderly population currently represents $12.4 \%$ of the total population (Maduwage,2019). "Sri Lanka is one country in the world that has a rapidly aging population. In 1953, the Sri Lankan elderly population was $5.4 \%$ and in 2003 , it was $10.8 \%$ of the total population. From 1953 to 2003, within 50 years, it has almost doubled in size. In 1981 and 2012, the elderly population was $6.6 \%$ and $12.4 \%$ of the total population, respectively. From 1981 to 2012, within 31 years, the Sri Lankan elderly population has further doubled. It is estimated that one in four Sri Lankans will be elderly by the year 2041" (Maduwage,2019).

"One of the mistakes done by marketers is neglecting this group by thinking that they have low income and spend less money. Even though they have less income, they are not in poverty compared to the population under age 34” ((EBRI, 2005). Silver aged population (age 50+) experience physical and mental changes during this period due to body postures, wrinkles, and changes in hair color and skin tones. Despite the bodily changes associated with aging, previous studies reported that the importance of appearance did not decrease with age (Kozar, 2005) and appearance was more important for women than for men (Oberg and Tornstam, 1999). It is the nature of humans that want to appear as young and beautiful as possible regardless of age (Hoffman, 1970). In any society, appearing old has been considered undesirable; thus, older individuals are often dissatisfied with their appearance. Past studies showed that women are more dissatisfied with their appearance than are men (e.g., Oberg and Tornstam, 1999). This dissatisfaction with one's self or appearance will lead to usage of grooming products (e.g. cosmetics, fashion clothing, accessories) and body modification activities (e.g. diet). In addition to the physical change, older individuals experience changes in social roles (e.g., retirement, loss of family members and friends) and develop new social relations. Studies have noted the importance of personal appearance and clothing in social interaction among silver aged people (e.g., Kaiser, 1997). A considerable percentage of urban silver-aged women in Sri Lanka get a pension or other cash income according to Asian Development Bank Report,2019.

By looking at Figures 1,2 and 3, it is implied that about $20 \%$ of urban women have fixed monthly income and they were used to work in organizations in their young and middleaged having many interactions with society. As well as this is an attractive market for marketers with lots of opportunities as one in four Sri Lankans will be elderly by the year 2041" (Maduwage,2019). Therefore, it is important to have a good understand the activities they perform during their silver age. Specially to know the activities they conducted to maintain their self-image (as it is one of the main problems, they encounter during the silver age (Kaiser, 1997)) will be important to fashion and cosmetic marketers. Therefore, this research is intended to explore how appearance management is used to improve/maintain the self-esteem of urban silver-aged women in Sri Lanka.

\section{Literature Review}

Rosenberg (1979) defined self-esteem as people's feelings about their worth or value of themselves. Self-esteem becomes increasingly important to gain the respect and appreciation of others (Malkanthie, 2019). People need to accomplish things and then have their efforts recognized. People need to sense that they are valued and by others and feel that they are contributing to the world (Maslow 1943). Being trendy and fashionable certainly transforms one's selfperception. 
Malkanthie, M.A.A., Kelum, W.G.S., KJM, 2021, 10 (01)

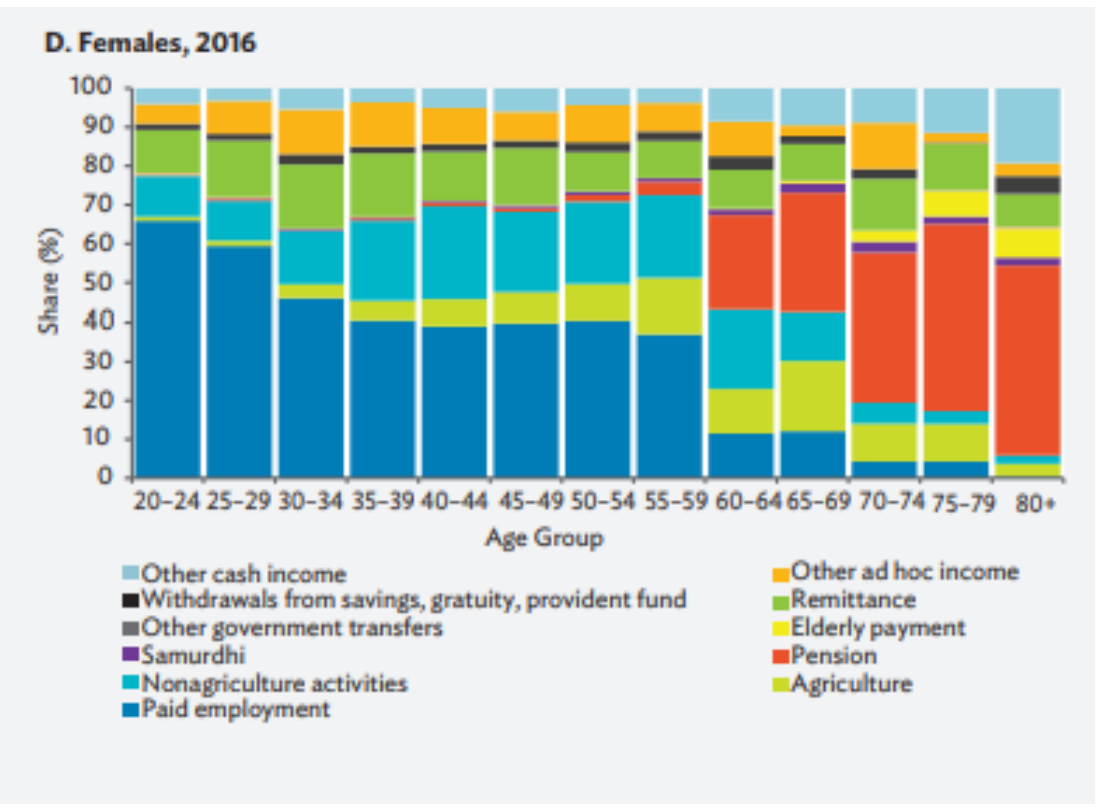

Figure 1: Income Sources of Women in Sri Lanka,2016

Source: Asian Development Bank Report,2016

\section{B. Urban Females}

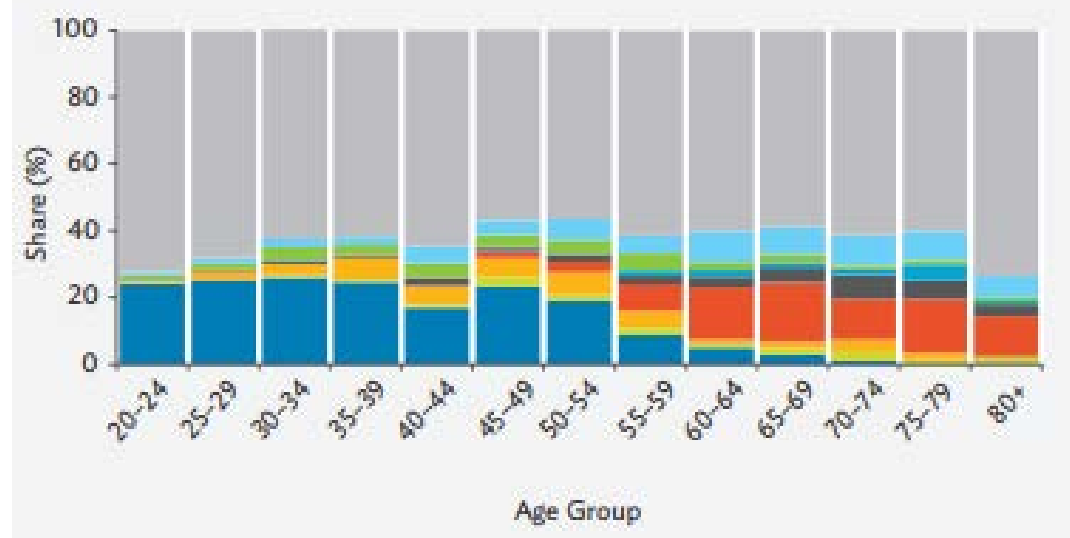

Figure 2: Income Sources of Urban Women in Sri Lanka,2016

Source: Asian Development Bank Report,2016 


\section{Rural Females}

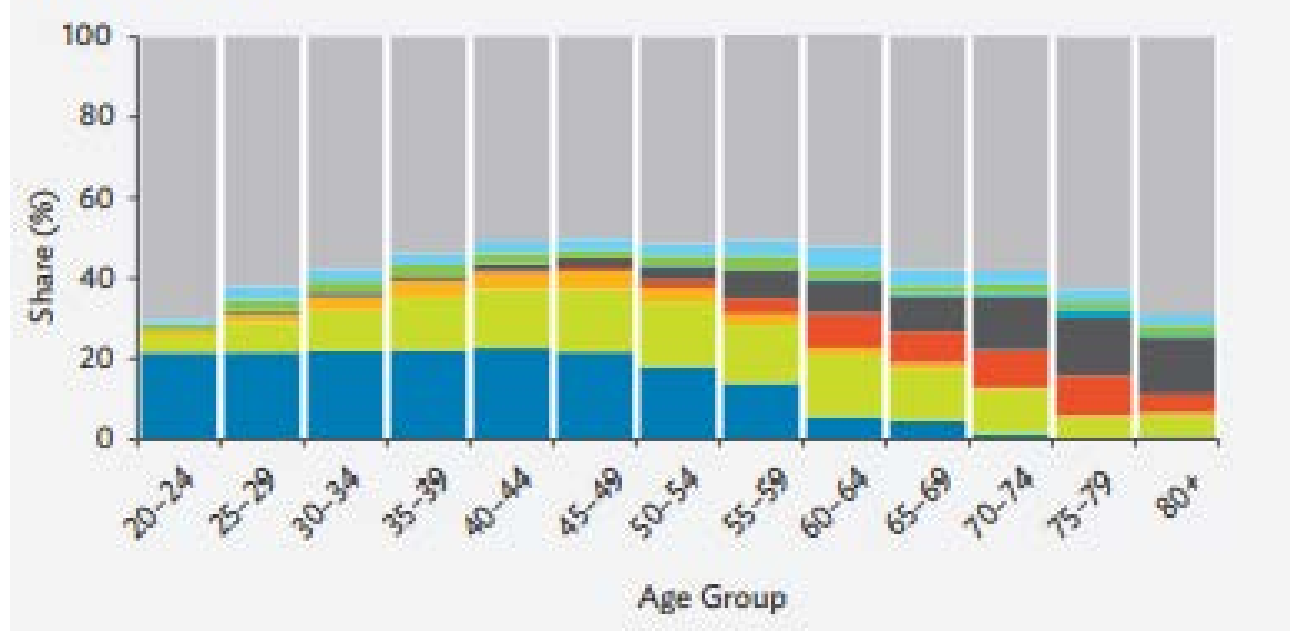

Figure 3: Income Sources of Rural Women in Sri Lanka,2016

Source: Asian Development Bank Report,2016

It won't just influence the level of confidence but also signifies how others perceive you (Akash, 2019). Physical appearance is a part of the self and is related to self-esteem. The feelings about personal appearance, along with other dimensions of the self, are the foundations of self-esteem (Joung \& Miller, 2006). "Appearance management is the sum total of our appearance presented to others, and the myriad ways we control it or make decisions regarding that presentation" (Reilly \& Rudd, 2007). People made decisions about the types of garments and accessories they wear, their color, fit and style, and the ways they assemble them into a complete "look." Appearance management also consists of behaviors such as grooming and personal hygiene, exercise and eating behaviors to help determine body shape and muscle tone, use of cosmetics and salon services, and invasive body alterations such as liposuction or implantation. Routine appearance management behavior carries little or no health risk, such as hair styling, makeup use, and aerobic exercise (Reilly \& Rudd, 2007). One of the significant non routine aspect of appearance is the dress, which can serve various purposes, depending on an individual's self-esteem level. For example, one study observed that clothing might be used as an adaptive function for individuals with low self-esteem and as an expressive function for individuals with high selfesteem. In other words, for those with low self-esteem, dress improves one's feelings about oneself, while for those with high selfesteem, clothing is used as a visual representation of a positive self-concept. Therefore, all individuals construct their appearances (i.e., engage in appearance management, though their motives and levels of management may differ based on selfesteem levels (Creekmore, 1974; Joung \& Miller, 2006). In another study, Joung \& Miller (2006) discovered that appearance management is a significant predictor of selfesteem in women aged 55 and older. Their results indicated that older women who frequently engage in appearance management behaviors have higher levels of self-esteem than those who are less involved in appearance management. In addition to the relationship between appearance management and self-esteem. 
Aging changes how others see us and how this affects our sense of self-esteem due to changes in social roles/activities (e.g. retirement), social relations (e.g. the loss of spouse), and appearance. Older adults may feel less important as they feel more dependent on others. As mentioned earlier, because our society places value on youth and beauty and women are more dissatisfied with their appearance, women are more vulnerable than men as they age. Moreover, dissatisfaction with one's appearance or dress may hinder social interaction (Kelly et al.,1974).

Therefore, an interest in appearance management may originate from different motives. Individuals with both higher and lower self-esteem may actively engage in appearance management, but for different reasons. Tyrchniewicz and Gonzales (1978) found an inverse relationship between selfesteem and a need for social approval through dress, supporting Creekmore's notion of the adaptive role of dress for those with low selfesteem (Kaiser, 1997). Dressing and other forms of appearance management, then, can be important props for individuals in social situations. Although women place more importance on appearance than do men, even as they continue to age (Oberg and Tornstam, 1999), little is known about how appearance management is used to improve/maintain the self-esteem of urban silver-aged women in Sri Lanka.

\section{Methodology}

\section{Research Approach}

This research adopted the inductive approach especially Interpretative method since this research is trying to understand the hidden behaviors and psychological matters of women who are passing the silver age and thereby trying to develop theories based on the findings. If it follows deductive approach key themes are often obscured, reframed, or left invisible because of the preconceptions in the data collection and data analysis procedures imposed by deductive data analysis.

\section{Purpose of the study}

The purpose of this research is to start with a general idea and uses this research as a medium to identify issues, that can be the focus for future research. Interpretative phenomenological analysis is used in this research to answer questions like what, why, and how. It is also expected to find out new and hidden insights of appearance management of silver-aged urban women in Sri Lanka and to know how it leads to increase the self-esteem of them.

\section{Research Choice}

The different aspects of the behavior of silver-aged women regarding their appearance management and self-esteem are difficult to predetermine as they can be varying according to the context and some internal and external factors. Further quantifying of human aspects may less effective. Therefore, it will be better to use a more flexible, greater unconstrained, and interaction allowing method rather than being inflexible and sticking to a predetermined question like in quantitative approach. Therefore, a qualitative study was selected for this research as it involves data collection of personal experiences, introspection, stories about life, interviews, observations, interactions, and visual texts which are significant to people life. This research area is highly personal, and people hesitate to discuss it in public. Even women might be hanging back to reveal their practices regarding appearance and selfesteem. Therefore, using a method that can be facilitated to maintain a less formal relationship with participants is important since it leads to understand the bigger picture and to gain an access to descriptive multiple realities via the elaborative responses.

\section{Population and Sampling}

The population of this study urban women, over fifty years of age in Sri Lanka, and the individual level was used since the researcher asked questions from women individually to discover their behavior. Qualitative studies often use purposeful or criterion-based 
sampling, that is, a sample that has the characteristics relevant to the research question or question (Nastasi, n.d) s, therefore, it states that Qualitative sample sizes should be large enough to obtain enough data to sufficiently describe the phenomenon of interest and address the research questions. The goal of qualitative researchers should be the attainment of saturation or the expected information level. So, the sample of this study consists of women who are in over fifty years who live in urban Sri Lanka. So, the sample size was twenty-five respondents.

\section{Sampling Technique}

According to the scenario of this research study purposive sampling was selected. As (Gentles, et al., 2015) A purposive sample is where a researcher selects a sample based on their knowledge about the study and population. The participants are selected based on the purpose of the sample; hence the Participants are selected according to the needs of the study therefore applicants who do not meet the profile are rejected. This study aims to obtain information about appearance management and fashion involvement of silver-aged urban women. As Stephanie, (2020) shows there are seven types of purposive sampling techniques. Among them, Homogeneous Sampling was utilized since it facilitated a collection of a very specific set of participants. The set may have similar background or experience. But the way women responding may be different due to some reasons like their behavior, attitudes, experience, and perceptions. Then it was facilitated to identify patterns and differences of each participant to derive answers for research questions and develop theories.

\section{Data Collection Instruments}

In this study, the main data collecting technique was in-depth interviews. According to (Showkat \& Parveen, 2017), indepth interviews are mostly long-duration, face to face, interviews. By using in-depth interviews, we were able to extract more detailed information about a relevant phenomenon or deep understanding of the subject and concepts. Further, according to Kvale (1996) "Knowledge is understood as buried metal and the interviewer is a miner who unearths the valuable metal".

Similarly, to the above statement employing a depth interview facilitated to find hidden psychological and social factors relevant to the appearance management and self-esteem of silver-aged women in urban areas, Sri Lanka. This study is carried out about the phenomena regarding psychological and physical changes experienced by women in the silver age. Hence in-depth interviews are more appropriate to answer research questions and meet the objectives of the research as it enabled the discovery of lots of information relevant to the topic. At the beginning of the interview, respondents were informed and explained the objective of the study to gain the willingness the participate since this topic is highly personalized and sensitive. After that, the time was needed to ask questions and clarify some matters deeply by probing. Therefore, the time duration taken for an interview was around fifteen minutes to thirty minutes.

\section{Interview Procedure}

In this study, semi-structured interviews have been used. As (Cropley, 2019) defines semistructured interviews are more structured and researchers already have some knowledge about the key issues and some expectations of what might emerge, or even wish to focus interviews to some extent. It provides great guidance to the direction of the discussions. In this method, a protocol or recording sheet was used as a guide. It is not necessary to have a list of specific concrete questions that are put to all respondents in a set order. To identify appearance management and selfesteem of silver-aged women, semistructured questions were mainly focused, and it further continued based on the answers given by the participants. It is also obtained information on the issues of interest with the 
assistant of the interview guide to remain the interview relevant to the research. Hence, it offered a better prospect of record data in writing during the actual interview. Throughout the interview, researchers were able to develop a good rapport with the participant by less formal and close relationships and were able to obtain the attitudes, perceptions, and experiences of the participants in their own words and can observe the non-verbal expressions like facial expressions gestures and postures of them which were direct closer to the reality. Further, it provided more elaborations on personal experiences, challenges during periods, and behavioral differences. Moreover, it will probe new areas and aspects which were unknown or untouched by being flexible. Voice Recordings and field notes were used to record the data during the interviews. later, data preparation (coding and themes identification) was done using transcribing of recorded data. Further, ethical consideration of this study was ensured by using information only for the study, avoiding the unnecessary question that harms the privacy of women and by using the convenient language for the respondents.

\section{Rigor of the Study}

Generally, rigor is conceptualized as quality in a study. As proposed by Guba \& Lincoln, 1985, a quality research study should satisfy four criteria: credibility, transferability, dependability, and conformability. Credibility is defined as the confidence that can be placed in the truth of the research findings. it is the equivalent of internal validity in quantitative research and is concerned with the aspect of truth-value of the findings. In this study, the peer debriefing technique was used to ensure the credibility of the findings. As Guba (1981) argues peer debriefing provides inquirers with the opportunity to test their growing insights and to expose them to searching questions. In this study, data findings were discussed with other researchers and had some comments and feedback. Then it was able to compare the similarities and differences of insights among researchers on the facts of the research and come across conclusions.

Transferability refers to the degree to which the results of qualitative research can be transferred to other contexts with other respondents (Lincoln \& Guba, 1985). In this study, a thick and rich description was used to ensure transferability. According to Lincoln and Guba (1989), the thick and rich description is not just the behavior and experiences of respondents, but their context as well such as observing and interpreting respondents' facial expressions, gestures, and postures. Since this study was trying to get highly personal matters of the respondents, using thick and rich description in collecting data was very useful for the researcher as the observation of body language can be generalized to other occasions as well.

According to Lincoln and Guba (1989) dependability refers to the stability of findings over time. To achieve dependability, the reporting of the process was done, and it helped to maintain a good understanding of the methods of the research and their effectiveness.

Conformability refers to the degree to which the findings of the research study could be confirmed by other researchers. The reason for checking conformability is to make free the findings from the typical human preferences and biases. Therefore, Conformability is concerned with neutrality and free from researchers' viewpoints and imaginations, but derived from the data (Baxter \& Eyles, 1997) As Lincoln and Guba (1985) argue conformability also can measure through Audit trials. This research used an audit trial to measure both dependability and conformability.

\section{Analysis of Data}

\section{Data Analysis Process}

Data for the research was gathered from semi-structured in-depth interviews from silver-aged women who were in age $50+$ who are living in the western province. Instead of 
that when asking some critical questions, observations like facial expressions were done to have an in-depth idea of some matters. The data from all these sources were required to combine in the analysis to derive answers for the research questions. The first step of the data analysis process is the conversion of data collected in the field to texts. Then, we were able to get familiar with the data collected. Afterward as mentioned in the methodology, the data was analyzed through thematic analysis. The data were coded manually using simple word codes. As a result, that, we were able to finalize four major themes in this research, i.e., selfesteem, appearance management, social participation, and fashion involvement. Subsequently, detailed analysis and interpretation of data under each theme were done.

\section{Analysis of Findings by Theme}

The thematic analysis is a data analysis strategy commonly used approach across qualitative studies (Castleberry \& Nolen, 2018) the goal of thematic analysis is to identify themes, patterns in the data that are important or interesting, and use these themes to address the research or say something about an issue. Therefore, identified themes should be relevant to the purpose and objectives of the research. As the first step of thematic analysis researcher must be familiarized with the transcripts of interviews by reading over them. With that familiarization, codes that emphasize the basic thing contained in an answer were generated. Later searched and reviewed those codes to identify themes by collating codes based on their common recurring patterns. As a result, the themes were finalized. Subsequently, detailed analysis and interpretation of data under each theme were done. Silver-aged women in Sri Lanka used clothes and cosmetics to enhance the appearance of them. By having in-depth interviews with respondents following themes were able to identify:

\section{Unique Self-identity}

According to the interviews had with the respondents, it was able to understand that silver aged women prefer to wear more fashionable clothes and try to maintain their appearance to have a unique identity. During the thematic analysis, the codes such as “different”, “unique.”, “special”, “distinct”, "unusual", "outstanding", were transformed to the theme "unique identity". As an example, participant No:15 of the interview mentioned "I feel happy when others say that I am beautiful today, nice clothes etc. I feel unique or outstanding and it improves my personality and identity. Since I am getting old, I used more cosmetics and nice clothes to enhance my appearance”. Since, selfidentity refers to stable and prominent aspects of one's self-perception (Sparks \& Shepherd, 1992), theme was developed in this research as "unique self-identity", using the codes given above in this research.

When the participant was asked on comparison of cloths with others, the same respondent (No.15) mentioned "I do not compare my clothes with others, but I look at them and have felt about their clothes. But I do not like to be one of them, I need a unique look appreciated by others." As well, I use cosmetics to enhance my appearance such as hair color, lipsticks, nail polish, eyebrows, foundation, etc.

An individuals' social identity is the view of themselves with the social and physical world where aspects of that view are contributed by the membership of certain social groups (Hogg, 2006). Regarding this, some participants in this study were motivated to moderate their clothing choices in anticipation of not only the perceived expectations of their friends but to achieve an internal consistency within their social group. 


\section{Internal Impression Management}

According to Leary and Kowalski (1990), "impression management" highlights how individuals control impressions to construct and manage an image that they believe will change or influence others' perceptions of themselves. Most of the respondents want to maintain or use fashion and cosmetics to enhance their appearance to impress others. During the thematic analysis, the codes such as “attract”, “appeal.”, “admire”, “appreciate by others" "improve appearance"," impressed by others" were transformed to the theme "internal impression management" as it really matches with the definition given with impression management. As an example, the first respondent of the interviews mentioned that she was a teacher and she used fashion and cosmetics to impress her students. "I am a teacher, and it is required to be pleasant, as only if the students will like me and will be able to attract the students to the lesson.

Respondent (07) of the interviews also mentioned that she had to meet clients and it was required to dress well to improve her appearance. But according to her fashion and dressing well is different but related. "we should wear matching clothes to the situation but that does not mean we should buy clothes every day to match the fashions available. I do not buy clothes frequently, but I buy clothes that enhance my look, attractive, appreciated by others, and impressed others.

An individuals' social identity is the view of themselves concerning the social and physical world where aspects of that view are contributed by the membership of certain social groups (Hogg, 2006). Regarding this, some participants in this study were motivated to moderate their clothing choices in anticipation of not only the perceived expectations of their friends but to achieve an internal consistency within their social group.

\section{External Impression Management}

Regarding the motivations behind moderation of self-presentation through clothing, this study aligned with the literature in the terms of the context of the individual's role and the perceived opinions of others. In the context of roles, individuals in the study understood that there were expectations associated with given roles. For example, the codes such as "neighbors expect", "friends want.", "family wants me to wear", "Relations' influence” were identified during the discussions and transformed to the theme "external impression management" "there is a certain standard of dress that is expected at work and you are just expected to meet it" (Respondent 3). Literature states that people are motivated to manage their impressions for those who are seen as being more powerful or hold a higher status than them. In terms of the "work" role, a participant stated that clothing is "[...] important in terms of my job because I am dealing with businesses and I need to present myself professionally" (respondent 02). Tice et al. (1995) found that one's self-presentation was changed significantly depending on the type of audience. These comments by participants can be seen with both the "self-esteem" and "belonging" motive. For specific roles, participants felt that dressing a particular way would allow for both a positive response from others and to be accepted into the given social circle. Further, regarding impression management, participants felt motivated to moderate their clothing choices based on the perceived opinions of others. "Knowing that there will be other women there who will be dressed in amazing clothes is sort of an incentive to dress nicely myself". (Respondent 01).

\section{Extended Self}

The extended self in appearance management Roach-Higgins and Eicher (1992) claimed that dress allows an individual to 
communicate their identity. Findings from the study aligned with this, with many of the women seeing their clothes and make-up as a representation of self. "I tend to purchase pieces that represent who I am and tell others about my personality and do makeup to show myself to others" indicates that this participant wishes to define herself through the possessions she consumes (Belk, 1988). Participants confirmed findings by Solomon and Schopler (1982) by acknowledging that clothing and make-up choice could significantly alter one's appearance and, thus affecting the way that others perceive the individual. For example, one woman stated, "I like to put effort into the way I dress, as I believe dressing well will have a positive effect on how people receive me" (Respondent 5), with another commenting that "they might even treat me differently" (Respondent 2) depending on her choice of appearance management. Therefore, the study aligned with extended-self theory with the participants confirming that they see appearance management as an extension of self and a way in which identity can be communicated to others.

\section{Discussion}

A link between an individuals' fashion orientation (self-fashioning, following, rejection, etc). and their self-concept has been discussed in prior research (e.g. Gutman and Mills, 1982; Goldsmith et al., 1999; Park and Burns 2005), but the common assumption is that those with high levels of self-esteem, or a strong self-concept, are more likely to exhibit self-confident and independent fashion behaviors, whereas those with low self-esteem are likely to be fashion followers or non-engaged with fashion. Since clothing is a visual representation of the self, silver aged women use articles of dress to construct and maintain an appearance cognitively coherently with the groups. Individuals are more concerned with their appearance management (in selecting clothes and cosmetics) to represent their image (Abrams and Hogg, 1988). As such, fashion is closely linked to the emotional well-being of silver aged women (Jantzen et al., 2006). These findings in the previous studies are completely match with the findings of this research. The findings of this research show how important to maintain appearance to silver aged urban women who had many social interactions during their middle and young ages. The findings show how helpful it to enhance their self-esteem and future self. And, how important to have a good appearance when they are with their peers, neighbors, and relations and how it improves their self-esteem. Hence, the finding was consistent with findings of previous studies that socially active elderly were interested in fashion and maintenance of their physical appearance (e.g., French and Fox, 1985; Lumpkin, 1985) Further, fashionable behavior is largely affected by the risk of getting old. The bad feeling of one's body image largely affect to the requirement of appearance management and one's self-esteem. One's attitude towards body image consists of two sub-constructs, which are body image evaluation/affect and body image investment. Body image evaluation/affect is an individual's satisfaction or dissatisfaction with his/her appearance. Body image investment is the "cognitive-behavioral importance of one's appearance and its salience to one's sense of self” (Cash et al., 2003). In addition, an individual's body image is affected by the positive or negative thoughts he/she has about him/herself. Positive thoughts can increase self-esteem levels and lead to success in many aspects of life. When, people are getting old, they feel bad about their body image. Then being fashionable silver aged women can increase their body image which leads to enhance one's self-esteem.

\section{Conclusion and Recommendation}


The women in this research used fashion as both social and symbolic capital (Bourdieu, 1984) to classify themselves concerning perceived social categories such as friends, peers, and their projected future self. This paper presents a typology of fashion identities, highlighting the clear differences that we see between individual women in the silver age and their engagement with fashion. Indeed, the belief that all women will similarly engage with fashion is outmoded even concerning the extent to which peer groups and the media influence a woman's fashion consumption. The women presented in this study show differing levels of security and independence concerning their fashion expression, and these differences are manifest in their consumption patterns and display of fashion-related behaviors. This paper illustrates the concept that, unlike previous notions of fashion independence and engagement with fashion, fashioninvolved categorizations of behavior are not always driven by sophistication, confidence, creativity, and low fear of risk. Instead, this study has shown that fashion innovativeness can be motivated by an overarching fear of the outcomes of being judged unfashionable - whether it is not fitting in, not having friends, not supporting one's job profile, or not being the perfect wife. The emotional context described here is the most important finding of this research and leads to a call for future examination of role-portrayal in fashion consumption, as a mechanism of fear-avoidance.

\section{References}

Abrams, D. and Hogg, M.A. (1988), Comments on the motivational status of selfesteem in social identity and intergroup discrimination, European Journal of Social Psychology, 8 (4),317-334.

Asian Development Bank Report, (2019), Growing Old Before Becoming Rich Challenges of An Aging Population in Sri Lanka, Metro Manila, Philippines

Baxter, J., \& Eyles, J. (1997), Evaluating qualitative research in social geography: establishing rigor in interview analysis, Transactions of the Institute of British Geographers, 22(4),505-525.

Belk, R.W. (1988), Possessions and the extended self, The Journal of Consumer Research,15(2), 139-168.

Bourdieu, P. (1984), Distinction a social critique of the judgement of taste, Routledge, London.

Cash, T.F., Jakatdar, T.A., \& Williams, E.F. (2003). The body image quality of life inventory: Further validation with college men and women. Body Image 1, 279-287. https://doi.org/10.1016/S1740-

1445(03)00023-8.

Castleberry, A., \& Nolen, A. (2018). Thematic analysis of qualitative research data: is it as easy as it sounds? Currents in Pharmacy Teaching and Learning, 10(6), 807-815.

DOI:https://doi.org/10.1016/j.cptl.2018.03.0 19.

Cropley, A., (2019), Introduction to qualitative research methods. Hamburg, Germany.

EBRI (2005), Income statistics of the population aged 55 and over, Retrieved from www.ebri.org/pdf/publications/books/databo ok/DB. Chapter percent 2006. pdf. 
French, W.A. and Fox, R. (1985), Segmenting the senior citizen market, The Journal of Consumer Marketing, 2(1),61-74, https://doi.org/10.1108/eb038822

Gentles, S. J., Charles, C., Ploeg, J., \& McKibbon, K. A. (2015). Sampling in Qualitative Research: Insight from an Overview of the Method Literature, The Qualitative Report, 20(11), 1772-1789.

Goldsmith, R.E., Beaudoin, M.A. and Beaudoin, P. (1999), Fashion innovativeness and self-concept: a replication, Journal of Product and Brand Management, 8(1), 7-18. https://doi.org/10.1108/10610429910257904

Guba, E.G. (1981), Criteria for assessing the trustworthiness of naturalistic inquiries. ECTJ, 29, 75

Guba, E. G., \& Lincoln, Y. S. (1989). Fourth generation evaluation, Newbury Park, CA: SAGE

Guba, E. G., \& Lincoln, S. Y. (1985). Establishing trustworthiness. Naturalistic Inquiry. Newbury Park, CA: SAGE Publications.

Gutman, J. and Mills, M.K. (1982), Fashion lifestyle, self-concept, shopping orientation, and store patronage: an integrative analysis, Journal of Retailing, (2), 64-86.

Hoffman, A. (1970), Clothing, in Hoffman, A.M. (Ed.), The Daily Needs and Interests of Older People, Charles C. Thomas, Springfield, IL, 286-99.

Hogg, M.A. (2006), Social identity theory, in Burke, P.J. (Ed.), Contemporary Social Psychological Theories, Stanford University Press, Palo Alto, CA, 111-136.

Jantzen, C., Ostergaard, P., and Sucena Viera, C.M. (2006), Becoming a woman to the backbone: lingerie consumption and the experience of feminine identity, Journal of Consumer Culture, 6 (2), 177-202.
Kaiser, S.B. (1997), The Social Psychology of Clothing: Symbolic Appearances in Context, 2nd ed., Fairchild, New York, NY.

Kozar, J.M. (2005), Older women's attitudes toward aging, appearance changes, and clothing, in Damhorst, M.L., MillerSpillman, K.A. and Michelman, S.O. (Eds), The Meanings of Dress, Fairchild, New York, NY, 359-63.

Kvale, S. (1996). Interview Views: An Introduction to Qualitative Research Interviewing. Thousand Oaks, CA: Sage Publications.

Leary, M.R. and Kowalski, R.M. (1990), Impression management: a literature review and two-component model, Psychological Bulletin,107 (1), 34-47.

Lumpkin, J.R. (1985), Shopping orientation segmentation of the elderly consumer, Journal of the Academy of Marketing Science,13 (2), 271-89.

Maduwage S. (2019), Sri Lankan 'silveraged' population, Journal of the College of Community Physicians of Sri Lanka, 25 (1), $1-3$,

https://doi.org/10.4038/jccpsl.v25i1.8205

Malkanthie M.A.A. (2019), Antecedents of Consumer Materialism: An exploration in Sri Lankan Context, Kelaniya Journal of Management, $08 \quad$ (1) 1-20, http://doi.org/10.4038/kjm.v8i1.7591

Nastasi, B. (n.d). Qualitative Research: Sampling \& sample size consideration, Retrieved from

https://www.studypool.com/documents/908 22/sampling-sample-size-considerationsadapted

Oberg, P. and Tornstam, L. (1999), Body images among men and women of different ages, Ageing and Society, 19, 629-44, https:// doi.org 10.1017/S0144686. 99007.394 
Malkanthie, M.A.A., Kelum, W.G.S., KJM, 2021, 10 (01)

Park, H.J. and Burns, L.D. (2005), Fashion orientation, credit card use, and compulsive buying, Journal of Consumer Marketing, 22 (3), 135-141, https://doi.org 10.1108/07363760510595959.135

Rafferty, K. (2011), Class-based emotions and the allure of fashion consumption, Journal of Consumer Culture, 11 (2), 239260, https://doi.org/10.1177/1469540511403398

Reilly A. \& Rudd N.A., (2007), Stress and Dress, Journal of Homosexuality, 52:3(4), 151-166, https://doi.org/10.1300/J082v52n03_07

Roach-Higgins, M.E. and Eicher, J.B. (1992), Dress and identity, Clothing and Textiles Research Journal, 10(4), 2-9.

Rosenberg, M. (1979), Conceiving the Self, Basic Books, New York, NY.

Sirgy, J.M. (1982), Self-concept in consumer behavior: a critical review, Journal of Consumer Research, 9 (3), 287-301.

Showkat, N. \& Parveen, H., (2017), Nonprobability Sampling, Research Gate, 1(9), 149-173

Solomon, M. and Schopler, J. (1982), Selfconsciousness \& clothing, Personality \& Social Psychology Bulletin, 8(3), 508-514.

Sparks, P., \& Shepherd, R. (1992). Self-Identity and the Theory of Planned Behavior: Assessing the Role of Identification with "Green Consumerism", Social Psychology Quarterly, 55(4), 388-399.

Stephanie G., (2020), Purposive Sampling (Deliberate Sampling), Retrieved from https://www.statisticshowto.com/purpo sive-sampling/

Tice, D.M., Butler, J.L., Muraven, M.B. and Stillwell, A.M. (1995), When modesty prevails: differential favorability of selfpresentation to friends and stranger, Journal

of Personality and Social Psychology, 69 (6), 1120-1138. 